\title{
Comorbidity of ADHD and allergic diseases in early adolescence: The role of parental smoking at home
}

\author{
Rosa S. Wong ${ }^{1,2,3} \cdot$ Keith T. S. Tung ${ }^{1} \cdot$ Hugo E. Leung ${ }^{1} \cdot$ Reena Chow $^{1} \cdot$ Gilbert T. Chua $^{1} \cdot$ Macro H. K. Ho ${ }^{1}$. \\ Winnie W. Y. Tso ${ }^{1}$. Genevieve P. G. Fung ${ }^{4}$ • Victoria Q. C. Tao ${ }^{5} \cdot$ Mike Y. W. Kwan $^{6} \cdot$ Terry Y. S. Lum ${ }^{2} \cdot$ lan C. K. Wong ${ }^{3,7}$. \\ Patrick Ip ${ }^{1}$
}

Accepted: 30 December 2021

(c) The Author(s), under exclusive licence to Springer Science+Business Media, LLC, part of Springer Nature 2022

\begin{abstract}
A growing body of research suggests an association between attention deficit hyperactivity disorder (ADHD) and allergic disorders, but little work has been done to explore the role of external factors such as parental smoking at home in the development of comorbid ADHD and allergic disorders. This study aimed to examine the association between allergic diseases and ADHD adjusted for exposure to parental smoking at home in early adolescents. We recruited 250 male (41.7\%) and 350 female (58.3\%) adolescents (mean [SD] age, 13.29 [0.52] years) via chain-referral sampling. Their ADHD symptoms were assessed by the parent proxy-report version of the Chinese Strengths and Weaknesses of Attention-Deficit/Hyperactivitysymptoms and Normal-behaviours (SWAN) rating scale. Data on the participants' history of clinician-diagnosed allergic diseases, family socio-demographics, and parental smoking habit were collected using a parent-completed questionnaire. Regression analyses were performed to examine the associations of interest. The levels of ADHD symptoms were comparable between allergic and non-allergic participants after controlling for child and family demographics and parental smoking at home. Notably, the risk of probable ADHD was particularly high in participants with food allergies (odd ratio $=4.51$, $\mathrm{p}=0.011$ ) but not in those with allergic rhinitis after adjusting for parental smoking at home. Our findings suggest that second-hand smoke exposure at home is a potential risk factor underlying the link between ADHD and allergic diseases. Current management guidelines should emphasize the importance of early identification and cessation of tobacco smoke exposure for prevention of comorbidity of ADHD and allergic disorders.
\end{abstract}

Clinical Trial Registration (if any): NA.

Keywords Allergic disease - Attention deficit hyperactivity disorder · Comorbidity $\cdot$ Second-hand smoke exposure · Environmental allergen
Abbreviations
OR Odd ratio
AR Allergic rhinitis
AD Atopic dermatitis

Patrick Ip

patricip@hku.hk

1 Department of Paediatrics and Adolescent Medicine, Queen Mary Hospital, The University of Hong Kong, Room 115, 1/F, New Clinical Building, 102 Pokfulam Road, Hong Kong, SAR, China

2 Department of Social Work and Social Administration, The University of Hong Kong, Hong Kong, SAR, China

3 Centre for Safe Medication Practice and Research, Department of Pharmacology and Pharmacy, The University of Hong Kong, Hong Kong, China
4 Department of Paediatrics, The Chinese University of Hong Kong, Hong Kong, SAR, China

5 Duchess of Kent Children's Hospital, Hong Kong, SAR, China

6 Department of Paediatrics and Adolescent Medicine, Princess Margaret Hospital, Hong Kong, SAR, China

7 Research Department of Practice and Policy, UCL School of Pharmacy, London, UK 


\section{Introduction}

Attention deficit hyperactivity disorder (ADHD) is one of the most common neurobehavioral disorders of childhood and adolescence. Individuals high in symptoms of ADHD encounter more challenging academic and social situations that could have lifelong effects on health and wellbeing (Faraone et al., 2003; Gillberg et al., 2004). While the exact aetiology of ADHD is not entirely clear, emerging research suggests that the underlying mechanism involves a complex interplay of genetic (e.g., dopaminergic and noradrenergic neurotransmitter deficiencies) and environmental factors (e.g., physical and emotional trauma during birth and early childhood) (Biederman \& Faraone, 2005; Faraone et al., 2005, 2014; Yüksel et al., 2021). Currently, 7.2\% of children worldwide are living with ADHD (Thomas et al., 2015). A previous study found that Hong Kong Chinese males studying in Grades 7, 8 and 9 of mainstream high schools exhibited an above-average prevalence of $8.9 \%$, with a prevalence of $3.9 \%$ observed among early adolescents (Leung et al., 1996, 2008).

\section{The Comorbidity of ADHD and Allergies}

Numerous studies, including meta-analyses (Miyazaki et al., 2017; Schans et al., 2017), have shown an association between ADHD and allergies. These diseases are clinical syndromes relating to immunological dysregulation, including hypersecretion of $\mathrm{Ig}-\mathrm{E}$, increased eosinophilic activity, and a predominantly T helper type 2 (Th2) cytokine oversecretion (Chen et al., 2013; Pelsser et al., 2009). A study of 8,201 participants from the Taiwan National Health Insurance Research Database showed an increased prevalence of allergic diseases including asthma (odds ratio $[\mathrm{OR}]=1.53$ ), allergic rhinitis (AR) $(\mathrm{OR}=1.59)$, and atopic dermatitis $(\mathrm{AD})(\mathrm{OR}=1.53)$ among ADHD patients when compared to the healthy controls (Chen et al., 2013). There are also reports highlighting the high degree of heterogeneity across findings pertaining to the association between symptoms of allergies and ADHD in children, which can differ in both direction and strength (van der Schans et al., 2020).

\section{Parental Smoking at Home as a Potential Cause of the Comorbidity}

The frequent co-occurrence of ADHD and allergic diseases suggests that these two distinct diseases may share some common casual pathways. In addition to genetic predisposition, for some individuals, the presentation of allergic and
ADHD symptoms could be resulted from exposure to environmental allergens. Despite mounting evidence showing the link between ADHD and allergic diseases (Miyazaki et al., 2017; Schans et al., 2017), much less is known about the co-occurrence of these diseases in relation to environmental allergens. It is possible that the relationship between ADHD and allergic diseases may not be causal but arise due to the exposure to shared environmental allergen. For example, second-hand smoke is a known risk factor for ADHD (Huang et al., 2021). Evidence from meta-analysis also support the association between environmental tobacco smoke exposure and allergic diseases such as allergic rhinitis (Saulyte et al., 2014), asthma (Wang et al., 2015), and eczema (Kantor et al., 2016) in childhood. Alarmingly, parental smoking at home is not uncommon. A previous survey study of Hong Kong primary 2-4 students found that $34 \%$ of them reported parental smoking and 19\% reported second-home smoke exposure at home (Wang et al., 2011). This social phenomenon presents a new research question as to whether repeated exposure to shared environmental allergen at home (e.g. tobacco smoke) could increase children's susceptibility to the comorbidity of ADHD and allergic diseases, which deserves further investigations.

\section{The Present Study}

Based on current evidence and knowledge gap, we identified second-hand smoke at home as a potential environmental allergen underlying the link of ADHD and allergic diseases. Specifically, we used a cross-sectional study design to investigate the potential differences in the strength of this comorbid association before and after adjusting for exposure to parental smoking at home. We hypothesized that the adjustment of exposure to parental smoking at home would change the estimate of the comorbid association between ADHD and allergic diseases.

\section{Method}

\section{Study Design and Participants}

This study adopted a survey approach to characterizing the exposure to parental smoking at home and the history of allergic diseases and ADHD symptoms. Data were from parents of Grade 7 or Grade 8 students who either participated in the Healthy Kids cohort study (Ip et al., 2016; Tso et al., 2019) or were enrolled in the schools where the cohort participants were attending. For Healthy Kids cohort participants, research assistants retrieved their contact information from the database and invited each family unit by phone. If they expressed an interest to join, the survey materials 
including questionnaires and information sheet and consent were mailed to them, and they were instructed to return the completed questionnaires to the research team by mail using the prepaid envelop. This approach has been shown to collect more valid responses than the online survey approach (Al-Salom \& Miller, 2019). For participants recruited through schools, survey hardcopies were sent to those schools consenting to join. Teachers would then distribute the questionnaires to the interested students and return the completed questionnaires to the research team afterwards. All parents of eligible students were invited to review the survey information and provide informed consent. Upon obtaining informed consent, parents of participating students completed questionnaires about home environment and their child's history of allergic diseases and ADHD symptoms and would receive an incentive of HKD 100 (USD 12.8) upon survey completion. The study protocol was approved by the Institutional Review Board of the University of Hong Kong/ Hospital Authority Hong Kong West Cluster (UW 18-057).

\section{Measures}

Parents rated their child's ADHD symptoms using the Chinese Strengths and Weaknesses of Attention-Deficit/Hyperactivity-symptoms and Normal-behaviours Questionnaire (SWAN) (Lai et al., 2013). The Chinese SWAN consists of 18 items on a 7-point scale ranging from -3 (far better than normal) to +3 (far worse than normal) (Lakes et al., 2012), the average of which is the ADHD-combined (ADHD-C) score. The items can be further divided with nine items for ADHD-inattentive type (ADHD-I) and the other nine items for ADHD-hyperactive/impulsive type (ADHD-HI). The average of these subset items is the subscale score. The Chinese SWAN has been validated and demonstrated good psychometric properties in Hong Kong (Lai et al., 2013). In the present study, Hong Kong locally relevant Chinese SWAN cut-offs ( 0.33 for boys and 0.39 for girls) were used to identify participants with probable ADHD (i.e., displaying symptoms with sufficient frequency, duration, and characteristics that pre-clinically fulfil the DSM-IV criteria for ADHD diagnosis). Furthermore, as the number of cases with physician-diagnosed ADHD in the present sample was too small for data analysis, we computed the raw Chinese SWAN score as a proxy for ADHD symptom severity.

In addition, parents were asked to indicate whether their child had been physician-diagnosed with asthma, AR, AD, and food allergies, as well as to provide child and family characteristics such as child age and gender, monthly family income, maternal education, and parental smoking habits at home.

\section{Data Analysis}

Descriptive statistics were used to describe demographic characteristics, ADHD symptoms, and responses to questions on parental smoking at home and allergic diagnosis. We used linear regression analysis to examine four models of concerning the relationship between ADHD symptoms and diagnosis of allergic diseases. In the first model, we examined the association between ADHD symptoms and allergic disease overall and by disease type. In the second model, the association of interest was controlled for other allergic diagnoses. The third model was further adjusted for demographic factors (i.e., child age and gender, monthly family income, and maternal education level). Monthly family income and maternal education level were included as covariates because of their strong associations with child health (Cooper \& Stewart, 2021; Cuartas, 2021). The fourth model was built upon the third model with further adjustment for exposure to parental smoking at home. We also used logistic regression analysis to study the adjusted association of dichotomous probable ADHD status with any or specific type of allergic disease that controlled for parental smoking at home and demographic factors. As the parental smoking at home variable had missing data on $35 \%$ of the cases, regressions were based on full information maximum likelihood estimation to maximize the analytical sample size. All the analyses were performed using SPSS 25.0 software, with $\mathrm{p}<0.05$ indicating statistical significance. As this is an exploratory study, analyses were not corrected for multiple testing (Bender \& Lange, 2001).

\section{Results}

The participant sample $(n=600)$ consisted of 250 males (41.7\%) and 350 females (58.3\%) (mean age: 13.3 years; range: $13-16$ years). All of them were living with parents at the time of survey. Their sociodemographic characteristics were shown in Table 1. 48 participants (12.3\%) had ever been exposed to parental smoking at home. $76(12.7 \%)$ were SWAN-screened positive of probable ADHD. Regarding history of allergic diseases, 279 participants $(46.5 \%)$ were reported to have at least one allergic diagnosis of interest. Specifically, there were 35 participants with asthma, 225 with $\mathrm{AR}, 86$ with $\mathrm{AD}$, and 41 with food allergy.

Table 2 shows the association between allergic diagnosis and continuous ADHD symptoms. The association of having at least one allergic diagnosis with ADHD symptoms was positive and significant in both unadjusted $(\beta=0.18$, $\mathrm{p}=0.027)$ and adjusted $(\beta=0.19, \mathrm{p}=0.023)$ models. The results of crude regression analysis showed non-significant associations between individual allergic diagnosis and ADHD symptoms. After adjusting for other allergic diseases 
Table 1 Subject characteristics

\begin{tabular}{|c|c|}
\hline Gender, $\mathrm{n}(\%), n=600$ & \\
\hline Female & $350(58.3)$ \\
\hline Male & $250(41.7)$ \\
\hline Age, mean(SD), $n=600$ & $13.29(0.52)$ \\
\hline Monthly family income, mean(SD), HKD'000, $n=588$ & $54.5(38.4)$ \\
\hline Maternal education level, $\mathrm{n}(\%), n=596$ & \\
\hline Bachelor degree or above & $207(34.7)$ \\
\hline Grade 10 to diploma & $273(45.8)$ \\
\hline Grade $\leq 9$ & $116(19.5)$ \\
\hline Parent smoking at home, $\mathrm{n}(\%), n=392$ & \\
\hline Never & $344(87.8)$ \\
\hline Seldom & $18(4.6)$ \\
\hline Sometimes & $20(5.1)$ \\
\hline Always & $10(2.6)$ \\
\hline Diagnosis of allergic diseases, $\mathrm{n}(\%)$ & \\
\hline Asthma, $n=596$ & $35(5.9)$ \\
\hline Allergic rhinitis, $n=599$ & $225(37.6)$ \\
\hline Eczema, $n=596$ & $86(14.4)$ \\
\hline Food allergy, $n=597$ & $41(6.9)$ \\
\hline Any one of the above, $n=600$ & $279(46.5)$ \\
\hline ADHD symptoms, $n=600$ & \\
\hline Positive SWAN ADHD-Combined screen, n(\%) & $76(12.7)$ \\
\hline Positive SWAN ADHD-Inattention screen, n(\%) & $87(14.5)$ \\
\hline Positive SWAN ADHD-Hyperactivity screen, n(\%) & $48(8.0)$ \\
\hline Combined score, mean(SD) & $-0.71(0.91)$ \\
\hline Inattention score, mean(SD) & $-0.46(0.95)$ \\
\hline Hyperactivity score, mean(SD) & $-0.95(1.01)$ \\
\hline
\end{tabular}

and demographics, the association between the diagnosis of asthma and ADHD symptoms became significant $(\beta=-0.41$, $\mathrm{p}=0.019)$. On the other hand, the association of AR with ADHD symptoms was significant only in the mutually adjusted model $(\beta=0.18, p=0.037)$. With the addition of exposure to parental smoking at home as a covariate in the model, the association of ADHD symptoms with allergic diagnosis became weaker for both overall and specific allergic disease groups, whereas parental smoking at home showed a significant and positive association with ADHD symptoms $(\beta=0.12, \mathrm{p}=0.015)$.

Table 3 shows the logistic associations of dichotomous probable ADHD status with overall and specific allergic disease types. The association between probable ADHD status and having at least one allergic diagnosis was statistically insignificant in the adjusted models. On the other hand, the mutually adjusted models showed a significantly higher likelihood of having probable ADHD among participants with $\mathrm{AR}(\mathrm{OR}=1.95, \mathrm{p}=0.010)$ and food allergy $(\mathrm{OR}=4.37, \mathrm{p}=0.001)$ when compared to those without the disease of interest. These associations remained significant after further adjusting for child and family demographics. However, when the effect of exposure to parental smoking at home was controlled, the association remained significant only with food allergy $(\mathrm{OR}=4.51, \mathrm{p}=0.011)$ but not with $\operatorname{AR}(\mathrm{OR}=1.83, \mathrm{p}=0.072)$.

\section{Discussion}

This study examined the association between allergic diseases and ADHD in early adolescents by means of evaluating ADHD as both continuous symptom and dichotomous positive SWAN-screen status variables in the analyses. In addition, we explored the change in the strength of association between allergic diseases and ADHD before and after adjusting for exposure to parental smoking at home. Results showed differential patterns of ADHD symptoms among allergic disease groups, with asthmatic participants showing fewer ADHD symptoms than those non-asthmatic participants. These patterns remained unchanged after adjusting for other allergic diagnoses as well as child and family demographics. However, with the addition of parental smoking at home as a covariate in the model, all allergic diseases showed non-significant associations with ADHD symptoms. Based on our preliminary findings, future research should adopt robust design to confirm whether exposure to parental

Table 2 Association between ADHD symptoms and diagnosis of allergic diseases

\begin{tabular}{|c|c|c|c|c|}
\hline & $\begin{array}{l}\text { Model A } \\
\beta(95 \% \mathrm{CI}, \mathrm{p} \text {-value) }\end{array}$ & $\begin{array}{l}\text { Model B } \\
\beta^{\text {a }}(95 \% \text { CI, p-value })\end{array}$ & $\begin{array}{l}\text { Model C } \\
\beta^{\mathrm{b}}(95 \% \mathrm{CI}, \mathrm{p} \text {-value })\end{array}$ & $\begin{array}{l}\text { Model D } \\
\beta^{c}(95 \% \mathrm{CI}, \mathrm{p} \text {-value })\end{array}$ \\
\hline Asthma & $-0.26(-0.60$ to $0.08, p=0.140)$ & $\begin{array}{l}-0.37(-0.72 \text { to }-0.02 \\
p=0.040)\end{array}$ & $\begin{array}{l}-0.41(-0.75 \text { to }-0.07 \\
\mathrm{p}=0.019)\end{array}$ & $-0.41(-0.88$ to $0.05, \mathrm{p}=0.082)$ \\
\hline Allergic rhinitis & $0.15(-0.02$ to $0.31, \mathrm{p}=0.076)$ & $0.18(0.01$ to $0.35, p=0.037)$ & $0.16(-0.01$ to $0.33, p=0.061)$ & $0.20(-0.01$ to $0.41, \mathrm{p}=0.062)$ \\
\hline Atopic dermatitis & $0.03(-0.20$ to $0.26, p=0.786)$ & $-0.01(-0.26$ to $0.24, p=0.943)$ & $0.04(-0.20$ to $0.29, p=0.725)$ & $-0.03(-0.34$ to $0.27, p=0.828)$ \\
\hline Food allergy & $0.12(-0.20$ to $0.44, \mathrm{p}=0.466)$ & $0.10(-0.25$ to $0.44, p=0.590)$ & $0.14(-0.20$ to $0.48, p=0.425)$ & $-0.07(-0.50$ to $0.36, p=0.753)$ \\
\hline
\end{tabular}

${ }^{a}$ Mutually adjusted for allergic disease

${ }^{\mathrm{b}}$ Model B further adjusted for child age and gender, monthly family income, and maternal education level

${ }^{\mathrm{c}}$ Model $\mathrm{C}$ further adjusted for parental smoking at home 
Table 3 Association between probable ADHD status and diagnosis of allergic diseases

\begin{tabular}{|c|c|c|c|c|}
\hline & $\begin{array}{l}\text { Model A } \\
\text { OR (95\%CI, p-value) }\end{array}$ & $\begin{array}{l}\text { Model B } \\
\text { OR }^{\mathrm{a}}(95 \% \mathrm{CI}, \mathrm{p} \text {-value })\end{array}$ & $\begin{array}{l}\text { Model C } \\
\text { OR }^{\mathrm{b}}(95 \% \mathrm{CI}, \mathrm{p} \text {-value })\end{array}$ & $\begin{array}{l}\text { Model D } \\
\text { OR }^{\mathrm{c}}(95 \% \mathrm{CI}, \mathrm{p} \text {-value })\end{array}$ \\
\hline Asthma $^{+}$ & $0.81(0.30$ to $2.56, \mathrm{p}=0.809)$ & $0.68(0.22$ to $2.10, p=0.506)$ & $0.61(0.19$ to $1.92, \mathrm{p}=0.398)$ & $0.53(0.11$ to $2.62, p=0.434)$ \\
\hline Allergic rhinitis $^{+}$ & $1.91(1.18$ to $3.10, p=0.009)$ & $1.95(1.18$ to $3.23, p=0.010)$ & $1.82(1.07$ to $3.07, p=0.026)$ & $1.83(0.95$ to $3.53, \mathrm{p}=0.072)$ \\
\hline Atopic dermatitis ${ }^{+}$ & $1.02(0.52$ t0 2.03, $\mathrm{p}=0.950)$ & $0.51(0.22$ to $1.17, \mathrm{p}=0.511)$ & $0.59(0.25$ to $1.37, \mathrm{p}=0.220)$ & $0.60(0.20$ to $1.81, \mathrm{p}=0.362)$ \\
\hline Food allergy $^{+}$ & $3.18(1.55$ to $6.54, \mathrm{p}=0.002)$ & $4.37(1.86$ to $10.29, \mathrm{p}=0.001)$ & $\begin{array}{l}4.88(2.00 \text { to } 11.87 \\
\mathrm{p}<0.001)\end{array}$ & $4.51(1.41$ to $14.43, \mathrm{p}=0.011)$ \\
\hline
\end{tabular}

\footnotetext{
+ Compared to those without the disease (reference group)

${ }^{a}$ Mutually adjusted for allergic disease

${ }^{\mathrm{b}}$ Model B further adjusted for child age and gender, monthly family income, and maternal education level

${ }^{\mathrm{c}}$ Model $\mathrm{C}$ further adjusted for parental smoking at home
}

smoking at home plays a role in the development of ADHD and allergic symptoms. Another finding of note is that the diagnosis of food allergy remained to have a strong association with probable ADHD after adjusting for parental smoking at home, yet participants with AR and those without were similar in terms of the risk of probable ADHD after controlling for the effect of parental smoking at home. This finding provides further support for the role of second-hand smoke exposure at home in contributing to the progression of comorbidity of allergic disease and ADHD.

This study reveals a mixed pattern of presentation of ADHD among allergic patients. Previous studies have shown that allergic inflammation could induce production of $\operatorname{IgE}$ at sites distal from the original location of allergic irritation, giving rise to inflammatory reactions via mast cell highaffinity IgE receptor (FceRI) in various tissues including neuroinflammation in the brain (Galli et al., 2008; Gould \& Sutton, 2008). Although the role of immunoglobulin E (IgE) in the pathogenesis and pathophysiology of allergic diseases is well established (Owen, 2007), some studies found that IgE levels differed by type of allergic diseases (Stone et al., 2010; Wittig et al., 1980). Furthermore, the expression of mast cell FceRI itself and its effector inflammatory function could be IgE dependent (Gould \& Sutton, 2008), suggesting that differences in IgE levels, among other factors, could potentially explain the manifestation of ADHD symptoms in allergic patients. Hence, quantification of IgE levels would be helpful to elucidate the IgE-FceRI mediated link between allergies and ADHD.

Another finding of note is the negative association between the diagnosis of asthma and ADHD symptoms in this study, whereas a considerable body of evidence in the literature points to a positive link (Miyazaki et al., 2017; Schans et al., 2017; Yang et al., 2014). Methodological limitations such as small sample size may have biased the findings of this study. However, a recent meta-analysis of the relationship between ADHD and asthma has highlighted the potential of publication bias in the literature, as negative findings could have been underreported (Cortese et al., 2018). In addition, it is known that cytokines are released during allergic reactions and can pass through the blood-brain barrier to activate neuro-immunological mechanisms, resulting in unregulated neuro-inflammation and autoimmune brain destruction (Banks \& Erickson, 2010). To prevent ADHD symptoms, adequate control of cytokines is needed and partly depends on the nature and frequency of allergic treatment. For example, the use of inhalers can quickly relieve asthma and breathlessness in 10-20 minutes, but AR treatments such as intranasal corticosteroids may take a day to achieve adequate symptom control (deShazo \& Kemp, 2020; Sawicki \& Haver, 2020). On the other hand, some studies reported an association between early antihistamine use and increased ADHD symptoms (Schmitt et al., 2018). Hence, future studies should clarify the direction and strength of effect of allergic treatment on ADHD symptoms in the affected patients.

In addition, our findings support the notion that secondhand smoke exposure is one of the risk factors for ADHD (Max et al., 2013). This study also adds to the current literature that the association between symptoms of ADHD and allergic disease could be weakened when there is no second-hand smoke exposure. This is consistent with evidence from the human and animal studies reporting an association between second-hand smoke exposure and ADHD (Huang et al., 2021). Previous studies have reported a graded association between exposure to second-hand smoke and behavioural problems in children (Zhou et al., 2014). Likewise, the links between second-hand smoke exposure and allergies are also well established (Braun et al., 2020). Indeed, mechanisms such as elevated cytokines, neurotransmitter alteration, and brain structure changes that underlie the development of ADHD and allergies could be activated through exposure to tobacco smoke (Braun et al., 2020; Huang et al., 2021; Lambrecht et al., 2019; Strzelak et al., 2018).

Apart from the findings about continuous ADHD symptoms, we also investigated the relationship between allergic 
diseases and dichotomous probable ADHD status. Given that participants who had probable ADHD were those with the highest levels of ADHD symptoms, the examination of probable ADHD status would be able to answer whether allergic diseases could predispose children and adolescents to the clinical diagnosis of ADHD. We found that food allergy and AR were most strongly associated with probable ADHD status. Specifically, participants with AR were 1.91 more likely to have probable ADHD than those without AR, and participants with food allergy were 3.18 more likely to have probable ADHD than those without food allergy. Nevertheless, when the effect of exposure to parental smoking at home was controlled, the differences in the likelihood of probable ADHD between participants with AR and those without became smaller, although the association between food allergy and probable ADHD remained strong. These results align with the notion that repeated exposure to environmental allergens such as second-hand smoke is a risk factor for AR symptoms (Lin et al., 2011) and could increase one's susceptibility to neurobehavioral diseases such as ADHD (Huang et al., 2021). In addition, this study revealed a strong association between food allergy and probable ADHD which was independent of exposure to parental smoking at home. It has been posited that the manifestation of ADHD symptoms in individuals with food allergy could be a hypersensitivity reaction towards food-derived allergens (de Theije et al., 2014). The resulting upregulation of proinflammatory cytokines may cause damages to multiple systems including respiratory, immune, and nervous system, which could be one possible explanation for the increase in ADHD symptoms among individuals with food allergy (Ferro et al., 2016; Jiang et al., 2018).

\section{Limitations}

In the present study, we used a validated measure to assess ADHD symptoms in a relatively large sample of early adolescents. We also proposed a new perspective explaining the association between ADHD and allergies as a function of exposure to second-hand smoke exposure at home. However, there were several limitations. First, this is a crosssectional study, and thus we cannot determine whether there is a causal link between ADHD and allergic diseases. Furthermore, parent-proxy reports of second-hand smoke exposure at home, allergic diagnoses, and ADHD symptom severity may involve recall bias. Second, participants were recruited via chain-referral sampling, which could limit the generalizability of the present findings to other populations. In particular, the small number of participants with allergic diagnoses or screened positive of probable ADHD may have influenced the reliability of the results. More longitudinal studies with robust features such as large sample size and use of electronic health records would be useful to ascertain the role of second-hand smoke exposure in the development of comorbidity between ADHD and allergic diseases and its underlying mechanism.

\section{Implications}

\section{Future Research}

This study provides evidence on the role of exposure to parental smoking at home as a risk factor for ADHD symptoms in allergic patients. Future research could consider examining the psychological impact of exposure to parental smoking at home on the child through qualitative approaches such as using photovoice which is an innovative way to reflect, talk, learn, and share affective experiences through a specific photographic technique (Tanhan \& Strack, 2020).

\section{Child and Public Health Professionals}

The providers should perform a detailed assessment of home environment and parental smoking behavior to inform their decision on whether the ADHD symptoms require therapeutic and pharmacological treatments or can be alleviated by eliminating the environmental allergens such as tobacco smoke. This is particularly pertinent during the COVID-19 pandemic when children spend more time at home or other indoor environments and thus could have a higher risk of inhaling contaminated air by second-hand smoke.

\section{Educators}

Child health and public health educators should train future providers to be cautious and conscious when interpreting symptoms, which could have consequences for diagnostic classification (Rosendal et al., 2013). Moreover, information on the impact of environmental allergens on ADHD symptoms among allergic patients can be integrated into the teaching process to prepare future practitioners. This can be done through providing academic reading and case studies, inviting affected parents to share their experiences, promoting research collaboration, and public seminars.

\section{Conclusion}

In this cross-sectional study, the levels of ADHD symptoms in early adolescents were found to vary by allergic diagnosis. Exposure to parental smoking at home appears to predispose individuals with allergies to ADHD symptoms particularly for those with AR. Our findings suggest that environmental 
factors such as exposure to second-hand smoke could create a favorable condition for the development of allergic and ADHD symptoms, thereby causing a spurious association between these two conditions. It is important for parents and clinicians to assess the impact of environmental allergens on the manifestation of ADHD symptoms in allergic children, particularly during the COVID-19 pandemic period when infection control measures such as home confinement are implemented. Avoidance of allergens such as tobacco smoke and timely administration of medications to relieve allergic reactions in early life stages are among the promising strategies to prevent the onset and progression of ADHD.

Acknowledgements We thank the schools, children, and parents for participation in this study. This study was supported by the Research Grants Council of the Hong Kong Special Administrative Region, China (General Research Fund Project Nos. 17606318).

Authors' Contributions Dr Rosa Wong contributed to this article including conceptualized the paper, analyzed the data, and wrote the initial draft. Mr Keith Tung conceptualized the paper, analyzed the data, and critically revised the manuscript. Mr Hugo E Leung and Ms Reena Chow participated in data collection, drafted the initial draft, and reviewed and revised the manuscript. Dr Gilbert Chua, Dr Marco Ho, Dr Winnie Tso, Dr Genevieve Fung, Dr Victoria Tao, Dr Mike Kwan, Prof Terry Lum and Prof Ian Wong provided critical feedback and edits to subsequent revisions of the manuscript. Dr Patrick Ip conceptualized and designed the study, coordinated and supervised data collection, and critically reviewed the manuscript. The corresponding authors attest that all listed authors meet authorship criteria and that no others meeting the criteria have been omitted. All authors approved the final manuscript as submitted and agree to be accountable for all aspects of the work

Funding This study was supported by the Research Grants Council of the Hong Kong Special Administrative Region, China (General Research Fund Project Nos. 17606318).

Data Availability The data that support the findings of this study are available on request from the corresponding author.

Code Availability Not applicable

\section{Declarations}

Financial Disclosure All authors have indicated they have no financial relationships relevant to this article to disclose.

Conflict of Interest All authors have indicated they have no potential conflicts of interest to disclose.

\section{References}

Al-Salom, P., \& Miller, C. J. (2019). The problem with online data collection: Predicting invalid responding in undergraduate samples. Current Psychology, 38(5), 1258-1264. https://doi.org/10.1007/ s12144-017-9674-9
Banks, W. A., \& Erickson, M. A. (2010). The blood-brain barrier and immune function and dysfunction. Neurobiology of Diseases, 37(1), 26-32. https://doi.org/10.1016/j.nbd.2009.07.031

Bender, R., \& Lange, S. (2001). Adjusting for multiple testing-when and how? Journal of Clinical Epidemiology, 54(4), 343-349.

Biederman, J., \& Faraone, S. V. (2005). Attention-deficit hyperactivity disorder. The Lancet, 366(9481), 237-248. https://doi.org/10. 1016/S0140-6736(05)66915-2

Braun, M., Klingelhöfer, D., Oremek, G. M., Quarcoo, D., \& Groneberg, D. A. (2020). Influence of second-hand smoke and prenatal tobacco smoke exposure on biomarkers, genetics and physiological processes in children-An overview in research insights of the last few years. International Journal of Environmental Research and Public Health, 17(9), 3212. https://www. mdpi.com/1660-4601/17/9/3212.

Chen, M.-H., Su, T.-P., Chen, Y.-S., Hsu, J.-W., Huang, K.-L., Chang, W.-H., Chen, T.-J., \& Bai, Y.-M. (2013). Comorbidity of allergic and autoimmune diseases among patients with ADHD: A nationwide population-based study. Journal of Attention Disorders, 21(3), 219-227. https://doi.org/10.1177/1087054712474686

Cooper, K., \& Stewart, K. (2021). Does household income affect children's outcomes? A systematic review of the evidence. Child Indicators Research, 14(3), 981-1005. https://doi.org/10.1007/ s12187-020-09782-0

Cortese, S., Sun, S., Zhang, J., Sharma, E., Chang, Z., Kuja-Halkola, R., Almqvist, C., Larsson, H., \& Faraone, S. V. (2018). Association between attention deficit hyperactivity disorder and asthma: A systematic review and meta-analysis and a Swedish populationbased study. The Lancet Psychiatry, 5(9), 717-726. https://doi. org/10.1016/S2215-0366(18)30224-4

Cuartas, J. (2021). The effect of maternal education on parenting and early childhood development: An instrumental variables approach. Journal of Family Psychology. https://doi.org/10.1037/fam00 00886

de Theije, C. G. M., Bavelaar, B. M., Lopes da Silva, S., Korte, S. M., Olivier, B., Garssen, J., \& Kraneveld, A. D. (2014). Food allergy and food-based therapies in neurodevelopmental disorders. Pediatric Allergy Immunology, 25(3), 218-226. https://doi.org/ 10.1111/pai.12149

deShazo, R. D., \& Kemp, S. F. (2020). Pharmacotherapy of allergic rhinitis. In J. Corren \& A. M. Feldweg (Eds.), UpToDate. https:// www.uptodate.com/contents/pharmacotherapy-of-allergic-rhini tis? search $=$ treatment $\% 20$ of $\% 20$ allergic $\% 20$ rhinitis \& source $=$ search_result\&selectedTitle $=1 \sim 150 \&$ usage_type $=$ default $\&$ displ ay_rank=1\#H1916966252

Faraone, S., Bonvicini, C., \& Scassellati, C. (2014). Biomarkers in the diagnosis of ADHD - promising directions. Current Psychiatry Reports, 16(11), 1-20. https://doi.org/10.1007/s11920-014-0497-1

Faraone, S., Sergeant, J., Gillberg, C., \& Biederman, J. (2003). The worldwide prevalence of ADHD: Is it an American condition? World Psychiatry, 2, 104-113.

Faraone, S. V., Perlis, R. H., Doyle, A. E., Smoller, J. W., Goralnick, J. J., Holmgren, M. A., \& Sklar, P. (2005). Molecular genetics of attention-deficit/hyperactivity disorder. Biological Psychiatry, 57(11), 1313-1323. https://doi.org/10.1016/j.biopsych.2004.11. 024

Ferro, M. A., Van Lieshout, R. J., Ohayon, J., \& Scott, J. G. (2016). Emotional and behavioral problems in adolescents and young adults with food allergy. Allergy, 71(4), 532-540. https://doi.org/ 10.1111/all.12829

Galli, S. J., Tsai, M., \& Piliponsky, A. M. (2008). The development of allergic inflammation. Nature, 454(7203), 445-454. https://doi. org/10.1038/nature07204

Gillberg, C., Gillberg, I., Rasmussen, P., Kadesjö, B., Söderström, H., Råstam, M., Johnson, M., Rothenberger, A., \& Niklasson, L. (2004). Co-existing disorders in ADHD - implications for 
diagnosis and intervention. European Child \& Adolescent Psychiatry, 13(1), I80-92. https://doi.org/10.1007/s00787-004-1008-4

Gould, H. J., \& Sutton, B. J. (2008). IgE in allergy and asthma today. Nature Reviews Immunology, 8(3), 205-217. https://doi.org/10. 1038/nri2273

Huang, A., Wu, K., Cai, Z., Lin, Y., Zhang, X., \& Huang, Y. (2021). Association between postnatal second-hand smoke exposure and ADHD in children: A systematic review and meta-analysis. Environmental Science and Pollution Research International, 28(2), 1370-1380. https://doi.org/10.1007/s11356-020-11269-y

Ip, P., Rao, N., Bacon-Shone, J., Li, S. L., Ho, F.K.-W., Chow, C.-B., \& Jiang, F. (2016). Socioeconomic gradients in school readiness of Chinese preschool children: The mediating role of family processes and kindergarten quality. Early Childhood Research Quarterly, 35, 111-123.

Jiang, X., Shen, C., Dai, Y., Jiang, F., Li, S., Shen, X., Hu, Y., \& Li, F. (2018). Early food allergy and respiratory allergy symptoms and attention-deficit/hyperactivity disorder in Chinese children: A cross-sectional study. Pediatric Allergy and Immunology, 29(4), 402-409. https://doi.org/10.1111/pai.12888

Kantor, R., Kim, A., Thyssen, J. P., \& Silverberg, J. I. (2016). Association of atopic dermatitis with smoking: A systematic review and meta-analysis. Journal of the American Academy of Dermatology, 75(6), 1119-1125. https://doi.org/10.1016/j.jaad.2016. 07.017 e1111.

Lai, K. Y. C., Leung, P. W. L., Luk, E. S. L., Wong, A. S. Y., Law, L. S. C., \& Ho, K. K. Y. (2013). Validation of the Chinese strengths and weaknesses of ADHD-symptoms and normalbehaviors questionnaire in Hong Kong. Journal of Attention Disorders, 17(3), 194-202. https://doi.org/10.1177/1087054711 430711

Lakes, K. D., Swanson, J. M., \& Riggs, M. (2012). The reliability and validity of the English and Spanish strengths and weaknesses of ADHD and normal behavior rating scales in a preschool sample: Continuum measures of hyperactivity and inattention. Journal of Attention Disorders, 16(6), 510-516.

Lambrecht, B. N., Hammad, H., \& Fahy, J. V. (2019). The cytokines of asthma. Immunity, 50(4), 975-991. https://doi.org/10.1016/j. immuni.2019.03.018

Leung, P., Hung, S.-F., Ho, T.-P., Lee, C.-C., Liu, W.-S., Tang, C.-P., \& Kwong, S.-L. (2008). Prevalence of DSM-IV disorders in Chinese adolescents and the effects of an impairment criterion. European Child and Adolescent Psychiatry, 17(7), 452-461. https://doi.org/ 10.1007/s00787-008-0687-7

Leung, P., Luk, S., Ho, T., Taylor, E., Mak, F., \& Bacon-Shone, J. (1996). The diagnosis and prevalence of hyperactivity in Chinese schoolboys. The British Journal of Psychiatry, 168, 486-496.

Lin, S. Y., Reh, D. D., Clipp, S., Irani, L., \& Navas-Acien, A. (2011). Allergic rhinitis and secondhand tobacco smoke: A populationbased study. American Journal of Rhinology \& Allergy, 25(2), e66-e71. https://doi.org/10.2500/ajra.2011.25.3580

Max, W., Sung, H.-Y., \& Shi, Y. (2013). Attention deficit hyperactivity disorder among children exposed to secondhand smoke: A logistic regression analysis of secondary data. International Journal of Nursing Studies, 50(6), 797-806. https://doi.org/10.1016/j.ijnur stu.2012.10.002

Miyazaki, C., Koyama, M., Ota, E., Swa, T., Mlunde, L. B., Amiya, R. M., Tachibana, Y., Yamamoto-Hanada, K., \& Mori, R. (2017). Allergic diseases in children with attention deficit hyperactivity disorder: A systematic review and meta-analysis. BMC Psychiatry, 17(1), 120. https://doi.org/10.1186/s12888-017-1281-7

Owen, C. E. (2007). Immunoglobulin E: Role in asthma and allergic disease: Lessons from the clinic. Pharmacology \& Therapeutics, 113(1), 121-133. https://doi.org/10.1016/j.pharmthera.2006.07. 003
Pelsser, L. M., Buitelaar, J. K., \& Savelkoul, H. F. (2009). ADHD as a (non) allergic hypersensitivity disorder: A hypothesis. Pediatric Allergy and Immunology, 20(2), 107-112. https://doi.org/10. 1111/j.1399-3038.2008.00749.x

Rosendal, M., Jarbøl, D. E., Pedersen, A. F., \& Andersen, R. S. (2013). Multiple perspectives on symptom interpretation in primary care research. BMC Family Practice, 14(1), 167. https://doi.org/10. 1186/1471-2296-14-167

Saulyte, J., Regueira, C., Montes-Martínez, A., Khudyakov, P., \& Takkouche, B. (2014). Active or passive exposure to tobacco smoking and allergic rhinitis, allergic dermatitis, and food allergy in adults and children: A systematic review and meta-analysis. PLOS Medicine, 11(3), e1001611. https://doi.org/10.1371/journal.pmed. 1001611

Sawicki, G., \& Haver, K. (2020). Acute asthma exacerbations in children younger than 12 years: Home/office management and severity assessment. In R. A. Wood, G. Redding, \& E. TePas (Eds.), UpToDate. https://www.uptodate.com/contents/acute-asthmaexacerbations-in-children-younger-than-12-years-home-officemanagement-and-severity-assessment

Schans, J. V., Çiçek, R., de Vries, T. W., Hak, E., \& Hoekstra, P. J. (2017). Association of atopic diseases and attention-deficit/hyperactivity disorder: A systematic review and meta-analyses. Neuroscience and Biobehavioral Reviews, 74(Pt A), 139-148. https:// doi.org/10.1016/j.neubiorev.2017.01.011

Schmitt, J., Buske-Kirschbaum, A., Tesch, F., Trikojat, K., Stephan, V., Abraham, S., Bauer, A., Nemat, K., Plessow, F., \& Roessner, V. (2018). Increased attention-deficit/hyperactivity symptoms in atopic dermatitis are associated with history of antihistamine use. Euoperan Jouranl of Allergy and Clinical Immunology, 73(3), 615-626. https://doi.org/10.1111/all.13326

Stone, K. D., Prussin, C., \& Metcalfe, D. D. (2010). IgE, mast cells, basophils, and eosinophils. The Journal of Allergy and Clinical Immunology, 125(2 Suppl 2), S73-80. https://doi.org/10.1016/j. jaci.2009.11.017

Strzelak, A., Ratajczak, A., Adamiec, A., \& Feleszko, W. (2018). Tobacco smoke induces and alters immune responses in the lung triggering inflammation, allergy, asthma and other lung diseases: A mechanistic review. International Journal of Environment Research and Public Health, 15(5). https://doi.org/10.3390/ijerp h15051033

Tanhan, A., \& Strack, R. W. (2020). Online photovoice to explore and advocate for Muslim biopsychosocial spiritual wellbeing and issues: Ecological systems theory and ally development. Current Psychology, 39(6), 2010-2025.

Thomas, R., Sanders, S., Doust, J., Beller, E., \& Glasziou, P. (2015). Prevalence of attention-deficit/hyperactivity disorder: A systematic review and meta-analysis. Pediatrics, 135(4), E994-E1001. https://doi.org/10.1542/peds.2014-3482

Tso, W., Chan, M., Ho, F. K., Rao, N., Li, A. M., Chan, K. L., Tiwari, A., Wong, I. C., Wing, Y. K., \& Van Voorhees, B. (2019). Early sleep deprivation and attention-deficit/hyperactivity disorder. Pediatric Research, 85(4), 449-455.

van der Schans, J., Cao, Q., Bos, E. H., Rours, G. I. J. G., Hoekstra, P. J., Hak, E., \& de Vries, T. W. (2020). The temporal order of fluctuations in atopic disease symptoms and attention-deficit/hyperactivity disorder symptoms: A time-series study in ADHD patients. European Child \& Adolescent Psychiatry, 29(2), 137-144. https:// doi.org/10.1007/s00787-019-01336-2

Wang, M. P., Ho, S. Y., \& Lam, T. H. (2011). Parental smoking, exposure to secondhand smoke at home, and smoking initiation among young children. Nicotine \& Tobacco Research, 13(9), 827-832. https://doi.org/10.1093/ntr/ntr083

Wang, Z., May, S. M., Charoenlap, S., Pyle, R., Ott, N. L., Mohammed, K., \& Joshi, A. Y. (2015). Effects of secondhand smoke exposure on asthma morbidity and health care utilization in children: A 
systematic review and meta-analysis. Annals of Allergy, Asthma \& Immunology, 115(5), 396-401. https://doi.org/10.1016/j.anai. 2015.08.005 e392.

Wittig, H. J., Belloit, J., De Fillippi, I., \& Royal, G. (1980). Age-related serum immunoglobulin $E$ levels in healthy subjects and in patients with allergic disease. The Journal of Allergy and Clinical Immunology, 66(4), 305-313. https://doi.org/10.1016/0091-6749(80) 90026-3

Yang, M. T., Lee, W. T., Liang, J. S., Lin, Y. J., Fu, W. M., \& Chen, C. C. (2014). Hyperactivity and impulsivity in children with untreated allergic rhinitis: Corroborated by rating scale and continuous performance test. Pediatrics and Neonatology, 55(3), 168-174. https://doi.org/10.1016/j.pedneo.2013.09.003

Yüksel, A. E., Doğan, N., Tahıllığlu, A., Bilaç, Ö., Uysal, T., \& Ercan, E. S. (2021). ADHD and its associations with pregnancy, birth, developmental and medical-related characteristics. Current Psychology. https://doi.org/10.1007/s12144-021-01817-1

Zhou, S., Rosenthal, D. G., Sherman, S., Zelikoff, J., Gordon, T., \& Weitzman, M. (2014). Physical, behavioral, and cognitive effects of prenatal tobacco and postnatal secondhand smoke exposure. Current Problems in Pediatric and Adolescent Health Care, 44(8), 219-241. https://doi.org/10.1016/j.cppeds.2014.03.007

Publisher's Note Springer Nature remains neutral with regard to jurisdictional claims in published maps and institutional affiliations. 